\title{
Pediatric critical procedures in the emergency department
}

\section{Ashley Alexandra Foster, Matthew Adam Eisenberg}

Division of Emergency Medicine, Department of Emergency Medicine and Pediatrics, Boston Children's Hospital, Harvard Medical School, Boston, MA, USA

\section{Dear Editor,}

We have read the article by Cabalatungan et al. ${ }^{1}$ published in Clinical and Experimental Emergency Medicine with great interest. In this study, data from the National Hospital Ambulatory Medical Care Survey between 2010 and 2014 was used to identify adult and pediatric patients undergoing critical procedures in the emergency department (ED) and estimated a single emergency physician performed pediatric central line insertion, cardiopulmonary resuscitation, and endotracheal intubation once every 3.2, 5.2, and 2.8 years, respectively. The authors concluded that general emergency physicians perform these procedures at a significantly lower rate compared to the same critical procedures on adult patients. ${ }^{1}$ We agree that this article highlights a fundamentally important finding-the infrequency of pediatric critical procedures in the ED setting.

This study lays the groundwork but does not answer the question-where and how frequent are pediatric critical procedures performed in an emergency setting? We hypothesize that there may be a particular hospital and ED types where critical pediatric procedures may be even less frequently performed than Cabalatungan et al. ${ }^{1}$ suggest. This is partly because the National Hospital Ambulatory Medical Care Survey data set includes representation from both general hospitals and freestanding pediatric facilities. ${ }^{2}$ Due to the possibility of uneven distribution of these procedures across different hospital types, physicians working within certain hospitals may perform critical procedures in children even less frequently while other physicians within freestanding pediatric facilities may have performed the majority of the procedures in the database. Future research and sub-analysis of procedures by ED type is warranted. This information will allow for identification of emergency physicians that are at highest risk for pediatric skill decay.

While the percentage of pediatric critical procedures performed in pediatric EDs is unknown, it is clear that they also happen infrequently. In one study, a pediatric ED reported that $63 \%$ of pediatric emergency physicians did not perform any successful endotracheal intubations in a 12-month period. ${ }^{3}$ An additional study noted within a single pediatric ED, chest compressions are performed a median of 3 minutes per pediatric emergency physician, per year. ${ }^{4}$ The deficit may be further exacerbated in an academic setting, where faculty frequently take a supervisory rather than hands-on role in procedural performance.

As a result, alternative experiences to keep procedural skills up-to-date and demonstrate skill maintenance are equally necessary for both pediatric emergency physicians and emergency physicians. Some of these alternative experiences may include: procedural courses, simulation, deliberate practice with appropriate feedback, or practice within different clinical settings such as the operating room. ${ }^{1,5}$ As it seems that pediatric critical procedures may be rare events regard-
Received: 7 May 2020

Revised: 3 June 2020

Accepted: 16 June 2020

Correspondence to: Ashley Alexandra Foster Division of Emergency Medicine, Department of Emergency Medicine and Pediatrics, Boston Children's Hospital, Harvard Medical School, BCH 3066, 300 Longwood Ave, Boston, MA 02115, USA

E-mail:AAFOSTER@partners.org ORCID https://orcid.org/0000-0002-3059-6218

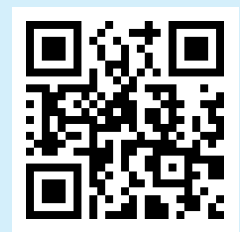

How to cite this article:

Foster AA, Eisenberg MA. Pediatric critical procedures in the emergency department. Clin Exp Emerg Med 2020;7(3):241-242. https://doi.org/10.15441/ceem.20.046

This is an Open Access article distributed under the terms of the Creative Commons Attribution Non-Commercial License (https:// creativecommons.org/licenses/by-nc/4.0/). 
less of practice environment, working together to optimize the skills of emergency physicians and pediatric emergency physicians is a critical next step as we continue to expand and encourage pediatric readiness in all EDs in the United States.

\section{CONFLICT OF INTEREST}

No potential conflict of interest relevant to this article was reported.

\section{REFERENCES}

1. Cabalatungan SN, Thode HC, Singer AJ. Emergency medicine physicians infrequently perform pediatric critical procedures: a national perspective. Clin Exp Emerg Med 2020;7:52-60.

2. Centers for Disease Control and Prevention. Ambulatory health care data [Internet]. Atlanta, GA: Centers for Disease Control and Prevention; 2020 [cited 2020 May 1]. Available from: https://www.cdc.gov/nchs/ahcd/new_ahcd.htm.

3. Mittiga MR, Geis GL, Kerrey BT, Rinderknecht AS. The spectrum and frequency of critical procedures performed in a pediatric emergency department: implications of a providerlevel view. Ann Emerg Med 2013;61:263-70.

4. Donoghue A, Abbadessa MK, Hsieh TC, Frankenberger W, Myers $\mathrm{S}$. How much cardiopulmonary resuscitation does a pediatric emergency provider perform in 1 year? A video-based analysis. Pediatr Emerg Care 2020;36:327-31.

5. Craig SS, Auerbach M, Cheek JA, et al. Preferred learning modalities and practice for critical skills: a global survey of paediatric emergency medicine clinicians. Emerg Med J 2019;36: 273-80. 